ical journals [editorial]. CMA7 1984;130:1412.

11. Bero LA, Galbraith A, Rennie D. The publication of sponsored symposiums in medical journals. N Engl f Med 1992;327:1135-40.

Competing interests: None declared.

DOI:10.1503/cmaj.1041329

\section{Online access to a for-profit CMAJ}

\ Tayne Kondro, quoting CMA Secretary-General Bill Tholl, reports that "Physicians will continue to receive their free subscription to CMA7 as a benefit of association membership 'for the foreseeable future" after CMA Publications is sold to CMA Holdings in January 2004. 'That's all to the good - but what then of CMAf's worldwide readers? Will access to $C M A 7$ remain free for all online users, despite the shift to for-profit status? I found it strange that this issue was not addressed in Kondro's news article.

\section{Adam L. Scheffler}

Independent researcher

Chicago, Ill.

\section{Reference}

1. Kondro W. CMAf enters for-profit market. CMA7 2004;171(11):1334.

DOI:10.1503/cmaj.1041759

\section{[Editor's note]}

O MAF's editors have addressed the topic of open access in this issue's Editorial (see page 149).

DOI:10.1503/cmaj.1041760

\section{Correction}

Tn part 2 of the series "Tips for learnIers of evidence-based medicine" the information in Fig. 1 did not fully correspond with the information provided in the text. Specifically, the data for hypo- thetical trial 2 in Fig. 1B should have been centred at $5 \%$ absolute risk reduction, as described in the text; instead, the figure showed trial 2 as being centred at about $6.5 \%$ absolute risk reduction. The corrected figure is presented here.

\section{Reference}

1. Montori VM, Kleinbart J, Newman TB, Keitz S, Wyer PC, Moyer V, et al. Tips for learners of evidence-based medicine: 2 . Measures of precision (confidence intervals). CMA7 2004;171(6): 611-5.

DOI:10.1503/cmaj.1041761

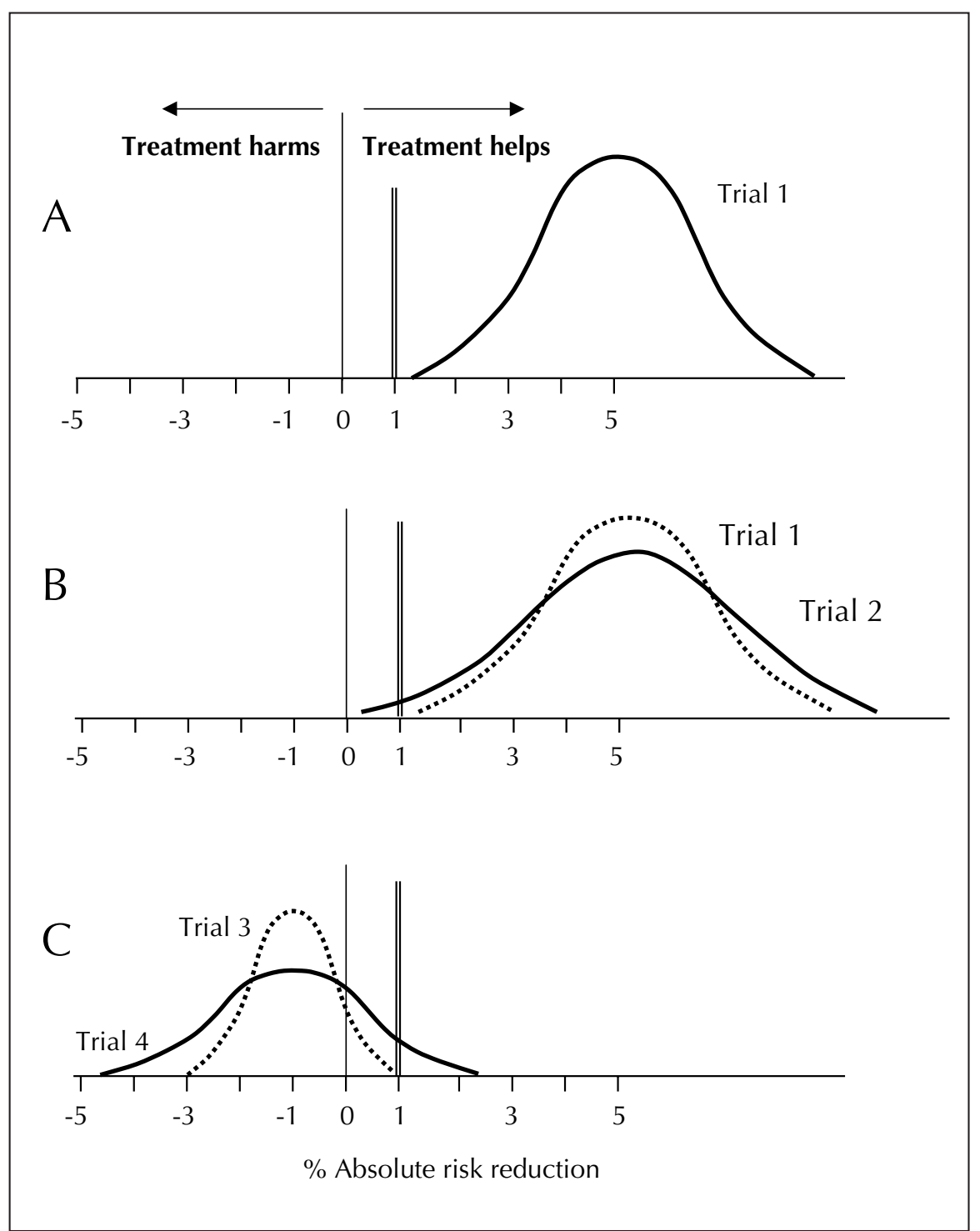

Fig. 1: Results of 4 hypothetical trials. For the medical condition under investigation, an absolute risk reduction of $1 \%$ (double vertical rule) is the smallest benefit that patients would consider important enough to warrant undergoing treatment. In each case, the uppermost point of the bell curve is the observed treatment effect (the point estimate), and the tails of the bell curve represent the boundaries of the $95 \%$ confidence interval. See the text ${ }^{1}$ for further explanation. 